\title{
Propriedades das hemoglobinas isoladas de artrópodos e moluscos do rio Amazonas (*)
}

\author{
Joseph Bonaventura ('); Maurizio Brunori $\left({ }^{2}\right)$; Michael T. Wilson ( ${ }^{3}$; Joseph P. Martin ('); Robert L. \\ Garlick ( $\left.{ }^{4}\right)$; Bonnie J. Davis ( 5
}

\section{Resumo}

Hemocianinas de 4 organismos habitantes do rio Amazonas foram isoladas e parcialmente caracterizadas. Três espécies de artrópodos (Dilocarcinus pagei cristatus, Silviocarcinus pardalinus e Macrobrachium amazonicum) possuem hemocianinas cujas estruturas das subunidades são provavelmente simples. Eletroforese regular e eletroforese SDS em disco de poliacrilamida revelaram predominantemente bandas simples e nenhum polimorfismo. O experimento de ligação do oxigênio mostrou que as 3 hemocianinas dos artrópodos possuem um grande efeito Bohr e dependência do $\mathrm{pH}$ no grau de interações das subunidades. A hemocianina do molusco Pila sp, foi estudada e o tamanho de sua subunidade parece similar à das outras hemocianinas dos moluscos, i.e., polipeptídeo 400.000 dalton. Na de hemolinfa do molusco Pila, provavelmente existe uma mistura de agregados de $100 \mathrm{~S}$ a $124 \mathrm{~S}$. As propriedades das ligaçōes do oxigênio das grandes moléculas da hemocianina de Pila sp, são notáveis por sua baixa cooperatividade e perda da forte dependência do $\mathrm{pH}$.

\section{INTRODUÇÃo}

Hemocianinas são proteínas de alto peso molecular ligando oxigênio, que ocorrem em dois filos, Arthropoda e Mollusca. Estas proteínas possuem cobre em seu sítio de ligação de oxigênio e mostram uma estequiometria de cobre para oxigênio de 2 para 1 .

Diversas publicações têm aparecido sobre as relações de estrutura e função como também o papel fisiológico das hemocianinas (Redmond, 1968; Van Holde \& van Bruggen, 1971; Lontie \& Witters, 1973; Antonini \& Bru- nori, 1974; Bonaventura et al., 1975; Bonaventura et al., 1977). É digno de nota que as hemocianinas dos Artropódos e Moluscos são estruturalmente diferentes e características. As hemocianinas dos artrópodos são compostas de subunidades com peso molecular variando de 70 a 80.000 daltons. Existem evidências de que seja significante a carga de heterogeneidade das subunidades de alguns artrópodos (Sullivan et. al., 1974, Bonaventura et al., 1975, Sullivan et al., 1976, Bonaventura et al., 1977). A forma molecular encontrada na hemolinfa dos artrópodes consiste em estados de agregação nos quais, hexâmeros, dodecâmeros, 24-mêros e 48-mêros são intermediários estáveis. As hemocianinas dos moluscos apresentam alguns contrastes quando comparadas à proteína dos artrópodos. As subunidades são muito grandes, 350 a 400.000 daltons, com múltiplos sítios de ligação de oxigênio. Estes são arranjados no distinto domínio de 50.000 unidades dalton (Lontie et al., 1973, Brouwer et al., 1976). Cada faixa possui 2 átomos de cobre e pode ligar uma molécula de oxigênio. Na hemolinfa, a forma da molécula é tipicamente de 20-mero, havendo um peso molecular de cerca de $9 \times 10^{6}$.

Uma considerável quantidade de informações tem sido acumulada sobre hemocianinas de moluscos habitantes de zonas temperadas (Bonaventura et al., 1977, observações não publicadas de Celia e Joseph Bonaventura). Nas hemocianinas dos artrópodos, heterogeneidade das subunidades e polimorfismo parecem ser comuns. Estudos do comportamento ele-

(*) - Versão original inglesa publicada em Comp. Biochem. Physiol. vol. 62 A (1). 1979.

(1) - Department of Biochemistry, Duke University Medical Center and Duke University Marine Laboratork, Beaufort, - North Carolina 28516.

(2) - Instituto di Chimica Biologica, Centro di Biologia Molecolare, Citta Universitaria, 00185 Rome, Italy.

( 3 ) - Department of Chemistry, University of Essex, Wivenhoe Park, Colchester CO4 35Q, England.

(4) - Department of Zoology. The University of Texas at Austin, Austin Texas 78712.

( 5 ) - Department of Biology, San Francisco State University, San Francisco, California 94132. 
troforético das hemocianinas dos caranguejos do Panamá e Venezuela sugerem que existe um pequeno polimorfismo das subunidades nas espécies examinadas (B. Sullivan, H.J. Fyhn e U.E.H. Fyhn, observações não publicadas).

Os organismos do rio Solimões habitam um ambiente muito especial. A água é temperada $29 \pm 1{ }^{\circ} \mathrm{C}$ durante o ano (Fisher, 1978). Estes organismos têm um problema adicional de sobrevivência na água com baixo conteúdo de oxigênio dissolvido. Nós estávamos, portanto, interessados em caracterizar as hemocianinas de organismos habitantes deste ambiente e comparar suas propriedades com outras hemocianinas conhecidas.

\section{MÉTodos e Resultados}

\section{PEQUENO CARANGUEJO VERMELHO}

O pequeno caranguejo vermelho, Dilocarcinus pagei cristatus (Bolt, 1969) $\left.{ }^{6}\right)$ foi fornecido por um pescador local. Não conseguimos saber exatamente o local de captura. Hemolinfa foi obtida do sinus pedal. A hemolinfa foi gotejada dentro de um tubo de ensaio e posteriormente coagulada à temperatura ambiente. O coágulo foi mecanicamente dispersado e diluído com $0,1 \mathrm{M}$ Tris, $0,01 \mathrm{M} \mathrm{CaCl}$, pH8. Depois de 10 minutos de centrifugação a 18.000 RPM numa Sorval, recolheu-se o sobrenadante contendo a hemocianina. No experimento destinado a observar as subunidades polimórficas, $50 \mu \mathrm{l}$ do sobrenadante foi adicionado a $200 \mathrm{ml} \mathrm{0,1M}$ Tris, 0,1M EDTA pH 9. Uns poucos microlitros desta solução foram usados para eletroforese regular e eletroforese em gel de SDS.

Eletroforese em gel de regular disco de 12 indivíduos do pequeno caranguejo vermelho mostraram que não há polimorfismo detectável das subunidades (Ornstein, 1964, Davis, 1964). Adicionalmente, contrastando com muitas das hemocianinas dos artrópodos, existem notavelmente poucos tipos de subunidades. De fato, o pequeno caranguejo vermelho pare- ce ter um único e pređominante tipo de subunidade. Eletroforese gel SDS (Weber \& Osborne, 1969) mostrou que existe homogeneidade com respeito ao peso molecular das subunidades da hemocianina do pequeno caranguejo vermelho, i.e. uma única e pronunciada banda na eletroforese de disco SDS-gel com peso molecular de cerca de 75.000. Baseandose nas condições eletroforéticas e da altíssima mobilidade das bandas eletroforéticas das hemocianinas dos artrópodos estudados, inferimos que elas são verdadeiramente subunidades de 75.000 daltons. Desde que os experimentos de ultra-centrifugação não foram realizados sob condições eletroforéticas, não podemos excluir a possibilidade de que as bandas que temos chamado de subunidades não sejam hexâmeros. Esta possibilidade, contudo, é muito improvável.

Os dados de ligação de oxigênio do pequeno caranguejo vermelho estão apresentados na Fig. 1. Esta hemocianina apresenta efeitos homo e heterotrópicos. Acima do pH examinado, o ploteado de Hill apresenta valores para $n_{1 / 2}$ de 2 a 3 . Os dados sugerem que a hemocianina é mais cooperativa a pH 7 e 8 do que a valores maiores ou menores. Há um forte e positivo efeito Bohr, com $\Delta \log \mathrm{P}_{1 / 2} \Delta \mathrm{pH}$ de $-0,8$ entre $\mathrm{pH} 7$ e 8 .

Ultracentrifugação da hemocianina do pequeno caranguejo vermelho a uma força iônica de 0.1 Tris, $0,01 \mathrm{M} \mathrm{CaCl} 2 \mathrm{pH} 8$, deu 1 pico de $14 \mathrm{~S}$ "schlieren" com indicações de uma pequena quantidade de produtos de dissociaçäo e associação para a esquerda e direita do limite. $O$ experimento ultracentrifugação indica que a espécie molecular predominante sob as condições da fig. 1 é o hexâmero.

\section{PEQUENO CARANGUEJO MARROM}

Hemocianina do pequeno caranguejo marrom Sylviocarcinus pardalinus (Gerstacker, 1956) $\left({ }^{\circ}\right)$ foi isolada e tratada de maneira análoga àquela em que foi tratado o pequeno caranguejo vermelho.

(6) - Abreviaturas usadas : EDTA, ácido etllenodiaminotetraacético bis-tris, bis (2-hidroxietil) imino-tris (hidroximetil) metano; $\mathrm{p}_{1} / 2$, a pressão do oxigênio expressa em milímetros de mercúrio, requerida para saturar a metade dos sítios da ligação do oxigênio da hemocianina; $n_{1} / 2$, a inclinação do ploteado de Hill para ligaçăo de oxigênio medido a $p_{1} / 2$; SDS, dodecilulfato sódio. 
A eletroforese em gel regular de disco de 8 indivíduos do pequeno caranguejo marrom não mostraram variações detectáveis de um indivíduo para outro, sugerindo uma ausência de subunidades polimórficas. Igualmente, o gel SDS mostrou uma única banda do material, havendo um aparente peso molecular de cerca de 75.000 .

Propriedades de ligação do oxigếnio desta hemocianina são mostradas na Fig. 2. O efeito Bohr da hemocianina do pequeno caranguejo

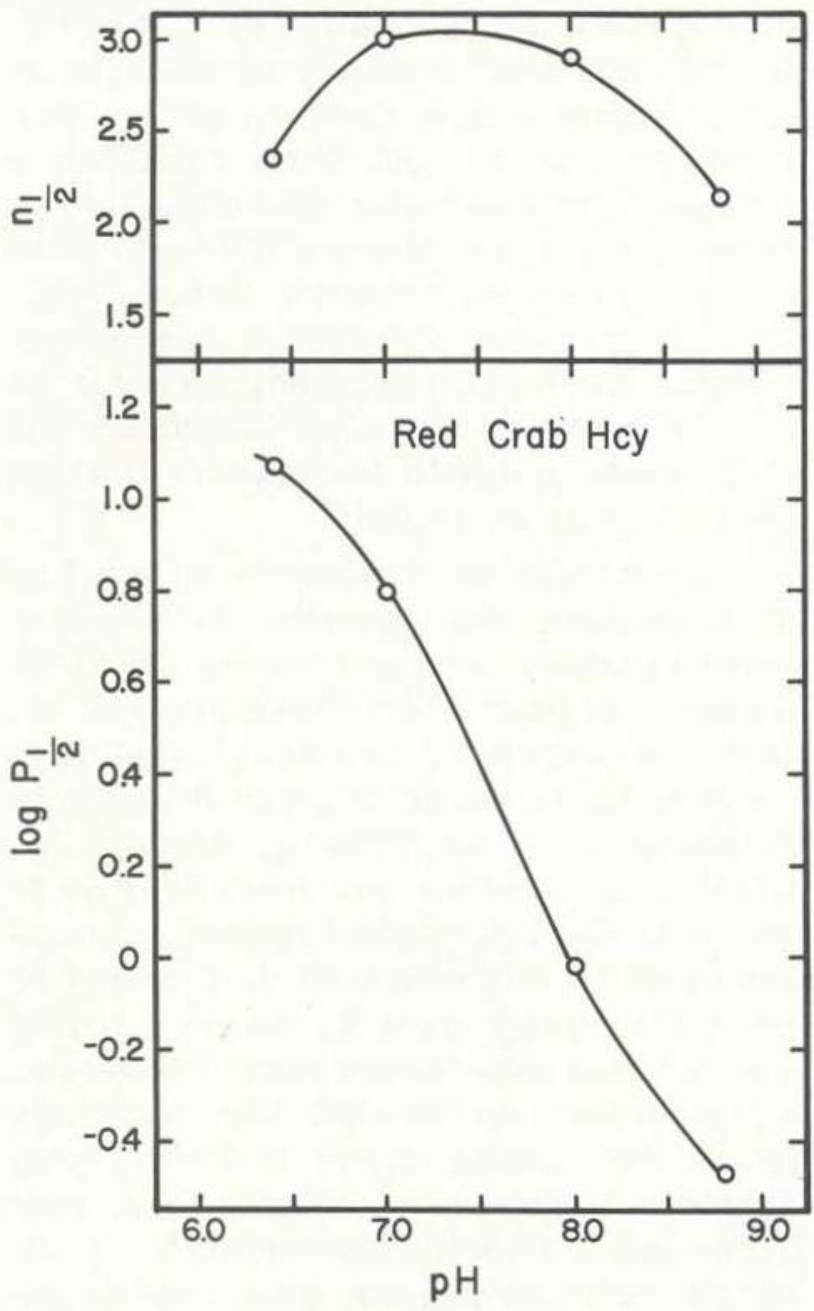

Fig. $1-\mathrm{A}$ dependência do $\mathrm{pH}$ da ligação do oxigênio da hemocianina de Dilocarcinus pagei cristatus. Experimentos realizados usando o processo tonométrico de Riggs \& Wolbach (1956). Experimentos realizados em $0,05 \mathrm{M}$ Bis-Tris (valores de $\mathrm{pH} \quad 7,0$ para baixo) e Tris (Valores de $\mathrm{pH}$ acima de 7,0 ) com tampãỏ contendo $10 \mathrm{mM}$ de cálcio. Experimentos realizados a $20^{\circ} \mathrm{C}$. Valores para a porcentagem de saturação da hemocianina com oxigênio foram calculadas do espectro de absorção coletado sobre o comprimento de onda de 400 a $450 \mathrm{~nm}$. marrom e do pequeno caranguejo vermelho são muito semelhantes. Somente ao redor de $\mathrm{pH}$ 9 é que a afinidade do oxigênio é diferente $\left(P_{1 / 2}=0,49 \mathrm{~mm} \mathrm{Hg}\right.$ para a hemocianina do pequeno caranguejo marrom e $0,34 \mathrm{~mm} \mathrm{Hg}$ para a hemocianina do pequeno caranguejo vermeIho). Outras diferenças nas duas hemocianinas são aparentes se examinarmos o feito do $\mathrm{pH}$ sobre a cooperatividade da ligação do oxigênio pelas duas hemocianinas. No caso do pequeno caranguejo marrom, aumentando o $\mathrm{pH}$ decresce a cooperatividade da hemocianina da ligação do oxigênio.

Ultracentrifugação da hemocianina do pequeno caranguejo marrom em força iônica 0,1 ; $0,01 \mathrm{M} \mathrm{CaCl}_{2} \mathrm{pH} 8$ mostrou dois picos "schlieren" simétricos aparecendo valores de $15 \mathrm{e}$

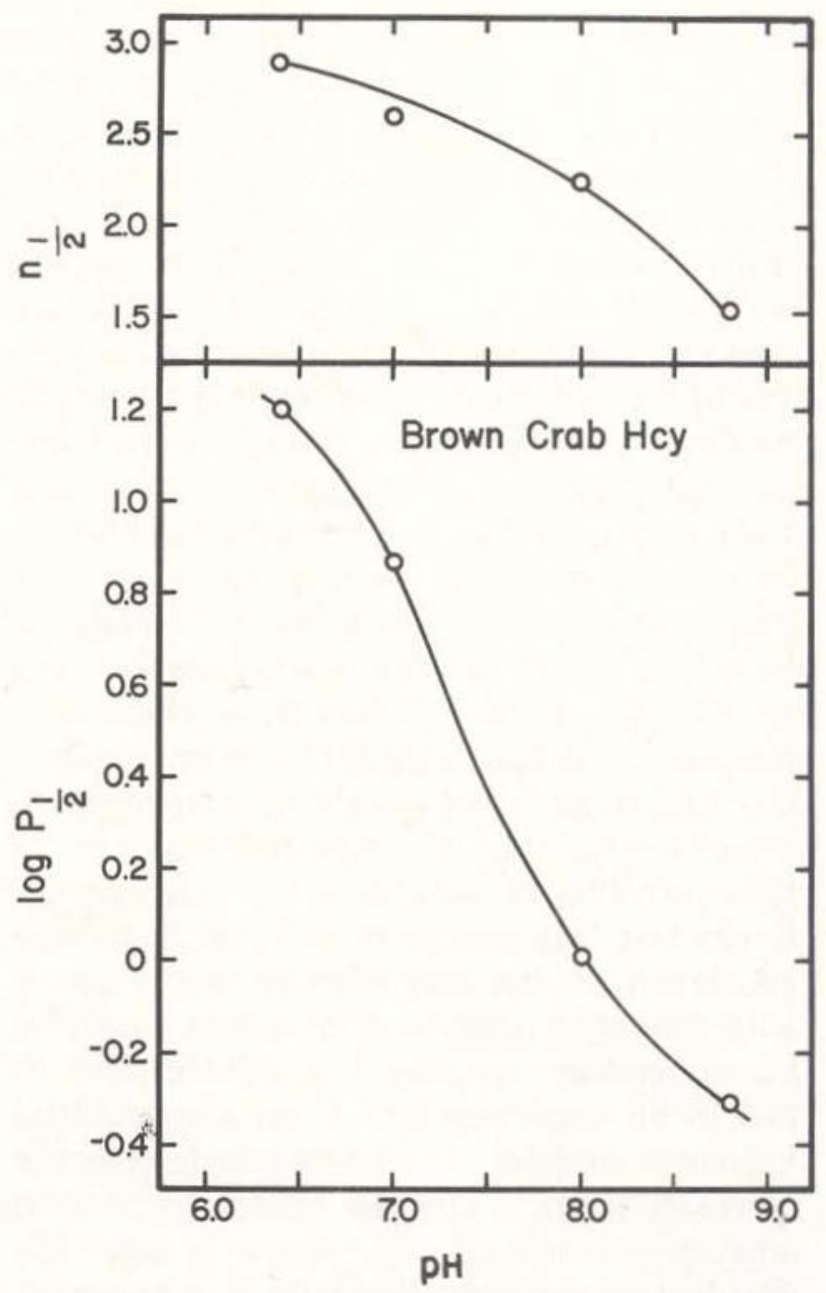

Fig. 2 - A dependência do pH da ligação de oxigênio da hemocianina de Sylviocarcinus pardalinus. Experimentos realizados sob condições idênticas àquelas da fig. 1 . 
22,3S. O pico 15S corresponde à espécie molecular da qual faz parte o hexâmero. Seu total é cerca de $70 \%$ do total do material presente sob estas condições. O pico 22,3S provavelmente corresponde ao dodecâmero. Sua quantidade é de cerca de $30 \%$ do material presente.

\section{HEMOCIANINA DE CAMARÃO}

Um camarão do capim flutuante do Amazonas, Macrobracium amazonicum foi coletado com a técnica de Rapiché. A elevação da água do paraná que conecta o lago Janauacá e o rio Solimões cobre áreas com vegetação flutuante que aparentemente proporciona refúgio para estes camarões. Mergulhando-se a rede por baixo do capim flutuante obtínhamos muitos camarões que variavam entre 1 a $3 \mathrm{~cm}$ de comprimento. Obtivemos a hemolinfa insertando um tubo capilar através da junção entre o tórax e a cauda, diretamente sobre o coração. A quantidade de hemolinfa obtida de cada camarão foi pequena (de 10 a $50 \mu \mathrm{l}$ ). Para a maioria dos estudos, a hemolinfa foi reunida e deixada coagular. O coágulo foi então disperso mecanicamente e diluído com um volume aproximadamente igual de 0,1M Tris $\mathrm{pH} 8$ contendo $0,01 \mathrm{M}$ de $\mathrm{CaCl}_{2}$. A mistura resultante foi centrifugada e o sobrenadante foi conservado para os estudos subseqüentes. Nos experimentos destinados a observar a variabilidade eletroforética, amostras individuais de hemolinfa foram obtidas e sopradas em uma película de "parafilm". Quatro a cinco volumes de 0,10M Tris, 0,1M EDTA foram adicionados às amostras individuais de hemolinfa. A solução resultante foi entåo retirada com um tubo hematócrito, fechado e centrifugado por 5 minutos. Uns poucos microlitros desta solução foram usados para eletroforese. Preparaçōes eletroforéticas de 8 indivíduos não mostraram nenhuma evidência de polimorfismo. 0 padrão do disco regular do gel eletroforético foi muito simples, uma banda rápida principal correspondendo a uma só espécie molecular, presumivelmente correspondendo a subunidades de hemocianina. Somando-se à banda rápida, havia uma banda lenta que provavelmente correspondiå a hexâmeros de subunidades de baixo peso molecular. Gel de SDS mostrou uma banda difusa, provavelmente duas vezes mais intimamente bandeadas e com um peso molecular de 75.000 .

Ligação de oxigênio nas hemocianinas dos camarões do capim flutuante do Amazonas na presença de $0,01 \mathrm{M} \mathrm{CaCl}{ }_{2}$ está mostrada na Figura 3. A hemocianina é fortemente dependente do $\mathrm{pH}$. O valor $\mathrm{p}_{1 / 2}$ é $120,2 \mathrm{~mm} \mathrm{Hg}$ a $\mathrm{pH}$ 6,82 e cai a $2,5 \mathrm{~mm} \mathrm{Hg}$ a $\mathrm{pH} 9$ ! Por toda essa faixa de $\mathrm{pH}$, a ligação de oxigênio é cooperativa, com valores de $n_{1 / 2}$ próximo de $3 . \mathrm{Na}$ ausência de cálcio, com pH 9,05, a afinidade do oxigênio é menor, com $p_{1 / 2}$ de $4,7 \mathrm{~mm} \mathrm{Hg}$. A cooperatividade observada na presença de cálcio é perdida na ausência de cátions divalentes $\left(n_{1 / 2}=1\right)$. Sob estas condições, a molécula é provavelmente dissociada em monômeros desde que pH alto e EDTA são geralmente efetivos em dissociar hemocianinas. Conseqüentemente, suspeitamos que os monômeros das hemocianinas dos camarões do capim flutuante do Amazonas possam ser não cooperativos na ligação do oxigênio e têm una baixa afinidade de oxigênio.

As cinéticas de dissociação do oxigênio da hemocianina dos camarões do Amazonas foram estudadas com uma técnica de combinação rápida descrita em (Bonaventura et al., 1974). A dissociação do oxigênio das hemocianinas dos camarões do capim flutuante do Amazonas é autocatalítica na presença de $0,01 \mathrm{M} \mathrm{CaCl}_{2}$, a $\mathrm{pH} 8,9 \mathrm{com}$ velocidades de 27 $\mathrm{sec}^{-1}$ a $43 \mathrm{sec}^{-1}$. A reação é também autocatalítica a pH 7,5 com velocidade de $55 \mathrm{sec}^{-1}$ a 95 $\mathrm{sec}^{-1}$. Uma grande parte da reação é perdida a $\mathrm{pH} 6,9$, mas naquelas que foram observadas, a taxa foi cerca de $170 \mathrm{seg}^{-1}$. Ultra centrifugação da hemocianina destes camarões, como também o oxiderivado na presença $\mathrm{CaCl}_{2}$, mostraram que a espécie predominante foi o hexâmero $16 \mathrm{~S}$, com pequena quantidade de dodecâmero 23S.

\section{HEMOCIANINA DE PILA SP}

O grande caracol, Pila sp. foi coletado por um pescador local. Hemolinfa foi obtida do "sinus pedal". A hemolinfa foi então passada através de uma coluna Sephadex G-25 equilibrada com $0,001 \mathrm{M}$ Tris, $0,01 \mathrm{M} \mathrm{Ca}^{2}+\mathrm{pH} 8.0$ equilíbrio do oxigênio foi medido com as ali- 
bis-tris ou Tris, de maneira que a absorbância quotas desta amostra diluindo-as com tampão do derivado oxigenado a $340 \mathrm{~nm}$ foi cerca de 0,6 e a força iônica final do tampão foi 0,10.

A hemoglobina de Pila sp. foi eletroforizada em gel regular de poliacrilamida $7,5 \%$ e em gel SDS. O pigmento não penetrou no gel regular de poliacrilamida e penetrou levemente no gel de SDS. Existe alguma indicação de proteínas com mais baixos pesos moleculares, mas estas representaram somente uma pequena fração do total das proteínas presentes no

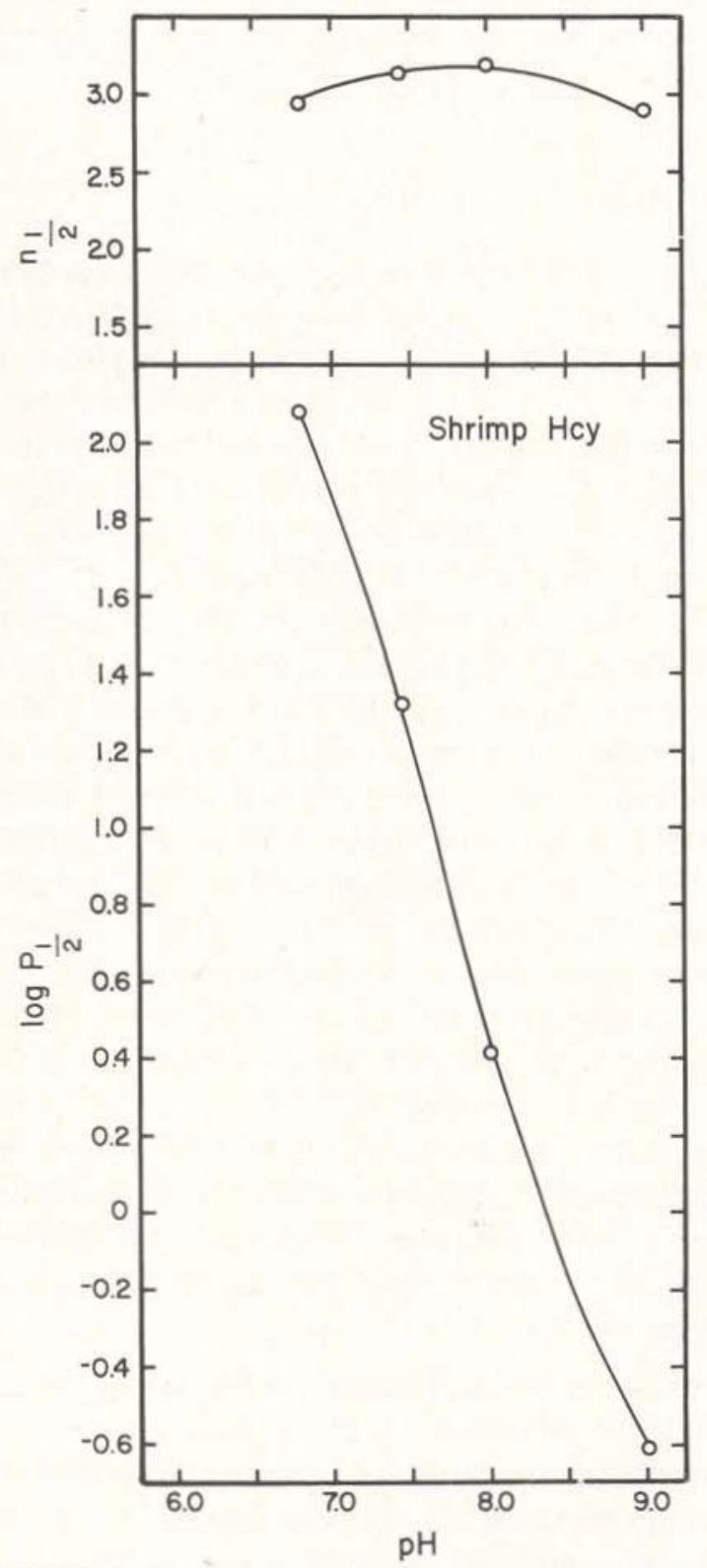

Fig. 3 - A dependência da ligação do oxigênio da hemocianina de Macrobrachium amazonicum. Condições experimentais idênticas às das fig. 1 e 2 . gel. Nós não temos marcadores de pesos moleculares para proteínas cujas subunidades sejam tão grande quanto às das hemocianinas dos moluscos (cerca de 400.000 daltons).

Entretanto, nossos resultados indicam que as subunidades da hemocianina de Pila sp. são também grandes, estando os pesos moleculares na ordem de várias centenas de milhares de daltons.

Sob todas as condições examinadas, existe pouca dependência do $\mathrm{pH}$ ou cooperatividade nas ligações do oxigênio das hemocianinas de Pila sp. Abaixo do pH 7,6, existe um pec,ueno e negativo efeito Bohr, $\Delta \log \mathrm{p}_{1 / 2} / \Delta \mathrm{pH}=$ 0,1 . Na faixa de $\mathrm{pH}$ entre 7,6 a 9 , existe um pequeno e positiva efeito Bohr, $\Delta \log \mathrm{p}_{1 / 2} / \Delta \mathrm{pH}$ $=0,05$. A cooperatividade das ligações de oxigênio medidas por $n_{1 / 2}$, alcançam $o$ valor máximo de 1,8 a pH 7,6 e em pH menor o valor de $n_{1 / 2}$ tende à unidade.

$\mathrm{Na}$ presença de $0,01 \mathrm{M}$ EDTA, a qual serve de quelantes para cátions divalentes, a afinidade do oxigênio da hemocianina do Pila sp. é aumentada. Isto é provavelmente um reflexo da diferença na afinidade do oxigênio das subunidades da hemocianina de Pila sp. relativa as moléculas totais. Sob estas condiçỏes a

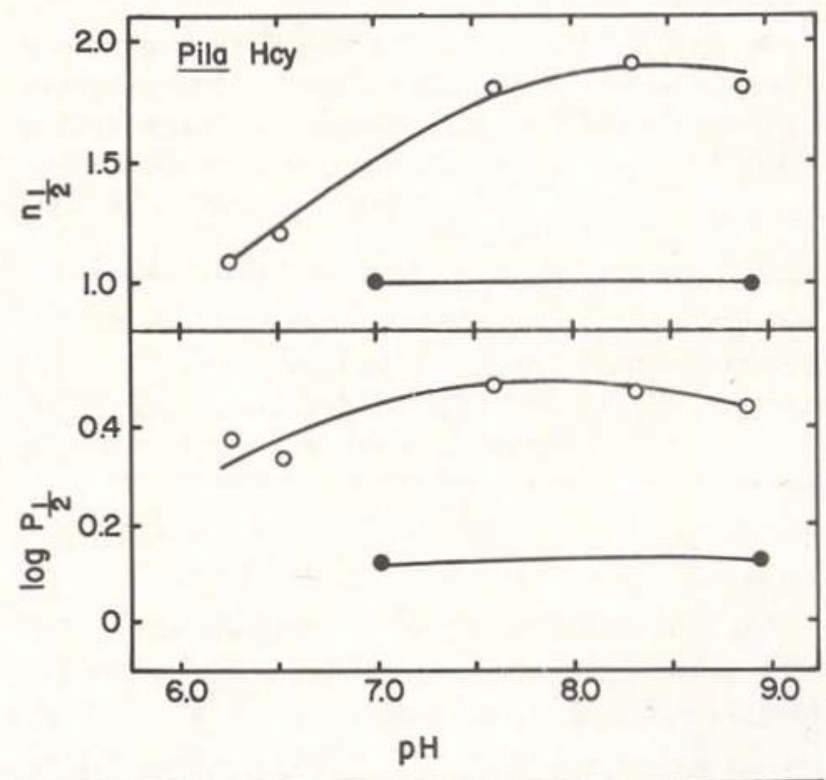

Fig. 4-A dependência do $\mathrm{pH}$ da ligação do oxigênio da hemocianina de Pila $\mathrm{sp}$. Experimentos realizados usando métodos similares aos das fig. 1-3. Os experimentos da fig. 4, entretanto, foram feitos a $29^{\circ} \mathrm{C}$. 
pH 7,0 e 8,9, a ligação de oxigênio é não cooperativa e a pressão do oxigênio necessária para meia saturação é $1,3 \mathrm{~mm} \mathrm{Hg}$.

A ultracentrifugação da hemocianina de Pila sp deu resultados não esperados. Em $\mathrm{I}=0,1$ Tris, $10 \mathrm{mM} \mathrm{CaCl}_{2}, \mathrm{pH}$ 8, duas distintas bandas apareceram. Os dois picos apresentaram coeficientes de sedimentação de $100 \mathrm{~S}$ a 124S. Existe alguma indicação de uma pequena quantidade de grandes agregados. O pico $124 \mathrm{~S}$ e picos maiores não são típicos de hemocianina de moluscos.

TABELA 1 - Ultracentrifugação das Hemocianinas dos organismos do rio Solimões em $I=0,1$ Tris, $0,01 \mathrm{M} \mathrm{CaCl}_{2}$ pH 8 .

\begin{tabular}{l|l}
\hline Organismo & $\begin{array}{l}\text { Espécies Sedimentados e sua } \\
\text { Prováveis Identidades }\end{array}$ \\
\hline Pila & $\begin{array}{l}100 \text { S ("molécula inteira") } \\
124 \mathrm{~S} \text { ("1,5 molécula") } \\
\text { Tendência para aumentar - } \\
\text { ordem de agregação }\end{array}$ \\
\hline $\begin{array}{l}\text { Camarão do capim } \\
\text { flutuante }\end{array}$ & $\begin{array}{l}16 \mathrm{~S} \text { (hexâmero) } \\
23 \mathrm{~S} \text { (dodecâmero, presente } \\
\text { em pequena quantidade) }\end{array}$ \\
\hline $\begin{array}{l}\text { Pequeno caranguejo } \\
\text { vermelho }\end{array}$ & $\begin{array}{l}\text { 14S (hexâmero) Apareceram } \\
\text { indicações de uma pequena } \\
\text { quantidade de dissociação e } \\
\text { produtos de associação para } \\
\text { a esquerda e direita do pico } \\
\text { schlieren }\end{array}$ \\
\hline $\begin{array}{l}\text { Pequeno caranguejo } \\
\text { marron }\end{array}$ & $\begin{array}{l}15 \mathrm{~S} \text { (hexâmero, 70\% do to- } \\
\text { tal) } \\
23.3 \mathrm{~S} \text { (dodecâmero, 30\% do } \\
\text { total) }\end{array}$ \\
\hline
\end{tabular}

A hemocianina de Pila também corre na ultracentrífuga sob condições usadas para diferenciar entre hemocianina $\propto-\beta-$ (Van Holde \& van Bruggen, 1971). Em acetado 0,1M, pH 5,7, três espécies sedimentares foram observadas com coeficientes de sedimentação de $76 \mathrm{~S}, 100 \mathrm{~S}$ e $113 \mathrm{~S}$. No mesmo tampão com $1 \mathrm{M} \mathrm{NaCl}$ três espécies sedimentares de coeficientes comparáveis foram observadas. A perda de dissociação sob estas condições indica que todas estas hemocianinas são do tipo $\beta$. Experimentos de ligação de oxigênio foram também realizadas sob estas condições. No tampão acetato não contendo $\mathrm{NaCl}$, e $\mathrm{p}_{1 / 2} \mathrm{e}$ $n_{1 / 2}$ foram 2,3 e 1,0 respectivamente. No mesmo $\mathrm{pH}$, mas na presença de $1,0 \mathrm{M} \mathrm{NaCl}$, os valores $p_{1 / 2}$ e $n_{1 / 2}$ foram 3,24 e 1,0 , respectivamente. Em acetato a $0,1 \mathrm{M}$ pH 5,7 a taxa de dissociação de oxigênio da hemocianina de Pila sp é homogênea com a constante de velocidade de primeira ordem de $11 \mathrm{sec}^{-1}$. Quando o mesmo tampão é feito $1 \mathrm{M}$ em NaCl, a reação permanece homogênea, mas a velocidade aumenta ao redor de $24 \mathrm{sec}^{-1}$.

\section{DISCUSSÃo}

As hemocianinas dos artrópodos provenientes do rio Solimões foram notáveis pela relativa simplicidade de suas subunidades e a aparente perda de subunidades polimórficas. Um grande número de hemocianinas examinadas mostraram grandes diversidade de subunidades (i.e. muitos componentes eletroforéticos) e polimorfismo (Bonaventura et al. 1977). Ou seja, diferentes padrões de subunidades eletroforéticas são encontradas quando diferentes indivíduos da mesma espécie são examinados. Tem sido proposto que a diversidade das subunidades das hemocianinas e hemoglobinas e polimorfismo podem ser correlacionados com a instabilidade termal do ambiente (Bonaventura et al. 1975). Embora nossas observações não provem isto, elas cedem evidências para essa proposta. Apoio adicional vem dos estudos de eletroforese de hemoglobina (Fyhn et al., 1978) já citado neste trabalho. As águas do rio Solimões onde o "Alpha Helix" estava ancorado são certamente termicamente estáveis. A variação de temperatura não é maior que $1^{\circ} \mathrm{C}$ ao longo do ano (Fisher, 1978).

O pequeno caranguejo vermelho Dilocarcinus pagei cristatus, e o pequeno caranguejo marrom Sylviocarcius pardalinus são ambos do mesmo tamanho e provavelmente habitam áreas similares. Existem pequenas mas significativas diferenças nas propriedades funcionais de suas hemocianinas. Cooperatividade na ligação de oxigênio da hemocianina de $D$. 
pagei cristatus é relativamente baixa a baixos e altos valores de $\mathrm{pH}$. Cooperatividade na ligação de oxigênio da hemocianina de $S$. pardalinus é alta a pH baixo e decresce monotonicamente quando o $\mathrm{pH}$ aumenta. $\mathrm{Em} \mathrm{pH} \mathrm{8,} \mathrm{na} \mathrm{pre-}$ sença de cálculo, a hemocianina $D$. pagei cristatus está preponderantemente na forma de 14S hexâmeros, enquanto a hemocianina de S. pardalinus em 1 tampão comparável é cerca de $70 \%$ hexamérica e $30 \%$ dodecamérica.

A hemocianina do camarão do capim flutuante, Macrobrachium amazonicum, é notável por sua afinidade do oxigênio ser altamente dependente do $\mathrm{pH}$. A pH 6,8, o valor de $\mathrm{p}_{1 / 2}$ é maior que $100 \mathrm{~mm} \mathrm{Hg}$ e a $\mathrm{pH} 9$ é menor que $1 \mathrm{~mm} \mathrm{Hg}$. A cooperatividade da ligação de oxigênio por esta hemocianina é relativamente alta $(n \sim 3)$ a todos valores de $\mathrm{pH}$. A estrutura quaternária de hemocianina do $M$. amazonicum é hexamérica, com uma pequena porcentagem de dodecâmeros a pH 8 na presença de $0,01 \mathrm{M}$ de cálcio.

Hemocianina dos grandes caracóis de água doce, Pila, consiste de típicas moléculas (100S) "inteiras" dos gastrópodos e "uma e meia" molécula (124S). Em Pila, estas estruturas são caracterizadas por um muito pequeno e negativo efeito Bohr. Este efeito Bohr negativo é paralelo ao decréscimo na cooperatividade da ligação do oxigênio de um pouco menos que 2 a um pH de 8,5 até cerca de 1 em pH de 6,25 . Pila aparentemente tem as hemocianinas $\propto$ e $\beta$, desde que a ultracentrifugação em acetato $0,1 \mathrm{M} \mathrm{NaCl} 1,0 \mathrm{pH} 5,7$ mostre que algumas moléculas dissociam-se ( $\propto \propto$ hemocianina) enquanto outras não se dissociam (a $\beta$ hemocianina). A hemocianina de Pila leopoldviliensis, por outro lado é toda do tipo $\beta$, isto é, ela não dissocia a pH 5,7 com tampão acetato contendo $1 \mathrm{M}$ de $\mathrm{NaCl}$ (Witters \& Lontie, 1968) .

Resumindo, a hemocianina dos astrópodos do rio Solimões parece diferir das espécies que habitam ambientes mais variáveis sendo monomórficas com respeito à carga NETA. Nosso estudo, porém, é o primeiro neste tipo com grandes espécies de água doce e, portanto, não podemos rejeitar a possibilidade de que $0^{*}$ ambiente constante iônico também contribui para a perda de polimorfismo. Nada pode ser dito sobre subunidades polimórficas em
Pila, porque nosso estudo eletroforético não determina proteínas de tão grande peso molecular. As propriedades funcionais da hemocianina de duas espécies de caranguejo são mais similares às dos caranguejos marinhos e o extremamente grande efeito Bohr do camarão do capim flutuante é diferente dos do camarão Paneus, os quais habitam ambientes marinhos (observações não publicadas de $\mathrm{J}$. Bonaventura, C. Bonaventura e M. Brouwer). As propriedades funcionais da hemocianina de Pila sp são notáveis dada a ausência da dedência do $\mathrm{pH}$ na ligação do oxigênio. Isto pode ser explicado pelo fato de que Pila tem um número de espécies de pesos moleculares distintos cujas propriedades funcionais devem diferir. Por exemplo, na hemocianina de Helix pomatia, a hemocianina $\propto$ tem um efeito dos Bohr positivo e a hemocianina $\beta$, um efeito Bohr negativo (Konings et al., 1969). Portanto em misturas complexas de tipos moleculares presentes em hemocianina de Pila, as diferenças nas características das propriedades funcional devem ser mascaradas. Melhor entendimento destas hemocianinas precisam aguardar a separação e caracterização de espécies moleculares puras.

Nossos resultados leva-nos a desejar mais dados acerca das espécies por nós estudadas no rio Solimões e subre as hemocianinas dos organismos habitando ambientes comparáveis. Tais estudos, feitos no "Alpha Helix" ou outros laboratórios poderiam ajudar-nos a entender as complexas relações entre a estrutura e função das hemocianinas dos moluscos e artrópodos.

\section{Agradecimentos}

Concessão PCM 75-06451 de U.S. National Science Foundation, auxilio a aspectos da fase IV da Expedição Amazônica "Alpha Helix" período de 1976 e 1977. Joseph Bonaventura é um pesquisador vinculado à American Heart Association e reconhecidamente agradece a subvenção de U.S. National Institutes of Healch e National Science Foundation. Maurizio Brunori agradece ao Conselho Nacional de Recursos (CNR) da Itália pela ajuda financeira. Michael T. Wilson expressa seus agradeci- 
mentos pelo auxílio da The Royal Society e a Duke University Biomedical Resources Support concedidos pelo National Institutes of Health. Bonnie J. Davies agradece a Joseph Henry. Marsh Fund of National Academy of Sciences e San Francisco State University pela ajuda financeira da viagem. Agradecemos aos Drs. Marius Brouwer e Thea Brouwer pela execução dos exeperimentos eletroforéticos e a Dra. Celia Bonaventura pela ajuda com a cinética dissociação do oxigênio. Auxíliơs adicionais referentes ao contrato ONR, ND0014-75-0190 (a J.B. ), auxílio $\mathrm{NIH}, \mathrm{HL}-15460$ (a J.B.) e auxílio $\mathrm{NIH}, \mathrm{BM}-21314$ (a A. Riggs) os quais estão profundamente agradecidos.

\section{SUMMARY}

Hemocyanins from four organisms inhabiting the Amazon River were isolated and partially characterized. Three arthropodan species (Dilocarcinus pagei cristatus, Silviocarcinus pardalinus and Macrobrachium amazonicum) posses hemocyanins whose subunit structure is remarkably simple. Regular and SDS polycrylamide disc electrophoresis revealed predominantly single bands and no polymorphisms. Oxygen-binding experiments showed that the three arthopodan hemocyanins possess large positive Bohr effects and $\mathrm{pH}$ dependence in the degree of subunit interaction. The hemocyanin of one mollusc, Pila sp., was studied and its subunit size appears to be similar to that of other molluscan hemocyanins, i.e., a 400,000 dalton polypeptide. In the hemolymph, Pila hemocyanin probably exists as a mixture of $100 \mathrm{~S}$ and $124 \mathrm{~S}$ aggregates. The oxygen binding properties of the large molecules of Pila hemocyanin are notable because of their low cooperativity and lack of a strong $\mathrm{pH}$ dependence.

\section{BIBLIOGRAFIA}

ANTONINI, E. \& BRUNORI, M.

1974 - Transport of Oxygen: Respiratory Proteins in Molecular Oxygen in Biology. In: Topics in Molecular Oxygen Research (Ed. Hayashi, O.) pp. 219-274.

BoLT, R.

1969 - The freshwater crabs of South American and their life histories. Ahh. sencke. nhery naturf. 9s, 518 Frankfurt am Main.
Bonaventura, C.; Sullivan, B. \& Bonaventura, J. 1974 - Effects of $\mathrm{pH}$ and Anions on Functional Properties of hemoglobin from Lemur fulvus fulvus. J. Biol. Chem., 249 : 3768-3775.

BonaventurA, J.; Bonaventura, C. \& Sullivan, B 1975 - Hemoglobins and Hemocyanins: Comparative Aspects of structure and function. J. Exp. Zool., 194 : 155-173.

1977 - Non-Heme Oxygen transport proteins. In: Oxygen and Physiological Function. (ed. Jobsis, F.). Texas, The Professional Information Library.

Brouwer, M.; Wolters, M. \& VAN Bruggen, E.F.J. 1976 - Proteolytic fragmentation of Helix po. matia a Hemocyanin: Structural domains in the polypeptide chain. Biochemistry, $15: 2618-2623$.

DAvis, B.J.

1964 - Disc Electrophoresis II. Method and application to human serum proteins. Annals of the New York Academy of Sciences, $121:$ 404-427.

FISHER, T.R.

1978 - Plâncton e produção primária em sistemas aquáticos da bacia da Amazônia Central. Acta Amazonica 8(4): Suplemento, (Este volume).

FYhN, U.E.H.; FYhN, H.J.; DAVIS, B.J.; Powers, D.A.; FINK, W.L. \& GARLICK, R.L.

1978 - Heterogeneidade de hemoglobina nos peixes da Amazônia. Acta Amazonica 8(4) : Suplemento. (Este volume).

Gerstacker, A.

1856 - Carcinologishe Beitrage. Arch. Naturg., $221: 101-162$

Konings, W.N.; Van Driel, R.; Van BRUggen, E.F.J. \& GRUBER, M.

1969 - Structure and properties of hemocyanin V. Binding of oxygen and copper in Helix pomatia hemocyanin. Biochem. Biophys. Acta, 194 : 55-66.

LONTIE, R.; Deley, M.; ROBBERECHT, H. \& WITters, R. 1973 - Isolation of small functional subunits of Helix pomatia hemocyanin after subtilisin treatment. Nature New Biology, $242: 180-182$.

LONTIE, R. \& WITTERS, R.

1973 - "Hemocyanin" In: Inorganic Biochemistry (Ed. Eichorn, G.L.) Amsterdam, Elsevier. pp. 344-358. 
ORNSTER, L.

1964 - Disc. Electrophoresis I. Background and theory. Ann. of the New York Academy of Science, $121: 321-349$.

REDMOND, J.R.

1968 - The respiratory function of hemocyanin. In: Physiology and Biochemistry of Hemocyanins, (ed. Ghiretti, F.) New York, Academic Press. pp. 5-23.

Riggs, A. \& Wolbach, R.A.

1956 - Sulfhydryl groups and the structure of hemoglobin. J. Gen. Physiol., 39 : 585605.

Sullivan, B.; Bonaventura, J. \& Bonaventura, C.

1974 - Functional differences in the multiple hemocyanins of Limulus polyphemus L. Proc. Natl. Acad. Sci., USA., 71 : 2558-2562.

Sullivan, B.; Bonaventura, J.; Bonaventura, C. \& GODETTE, G.

1976 - Hemocyanin of the Horseshoe Crab.
Limulus polyphemus. I. Structural Differentiation of the Isolated Components. J. Biol. Chem., 251 : 7644-7648.

Van Holde, K.E. \& VAN BRUgGen, E.F.J.

1971 - "The hemocyanins" In: Subunits in Biological Systems, (ed. Timasheff, S.H. \& Fasman, G.D.) New York, Marcel Dekker. pp. 1-53.

WEBER, K. \& OSBORNE, M.

1969 - The reliability of molecular weight determinations by Dodecyl Sulfate Polyacrylamide Gel Electrophoresis. J. Biol. Chem., 244 : 4406-4412.

WITTERS, R. \& LONTIE, R.

1968 - "Stability Regions and Amino Acid Composition of Gastropod Hemocyanins" In: Physiology and Biochemistry of Haemocyonins, (ed. Ghiretti, F.) New York, Academic Press. p. 61-73 